\title{
Switching patients from preserved prostaglandin- analog monotherapy to preservative-free tafluprost
}

This article was published in the following Dove Press journal:

Clinical Ophthalmology

I8 May 201 I

Number of times this article has been viewed

\section{Anton Hommer' \\ Friedemann Kimmich ${ }^{2}$ \\ 'Sanatorium Hera, Vienna, Austria; ${ }^{2}$ eyecons, Pfinztal, Germany}

Correspondence: Friedemann Kimmich eyecons, Woeschbacherstr. 37 D-76327 Pfinztal, Germany

Tel +49 72I 4647234II

Fax +49 72I 46472349

Email f.kimmich@eyecons.de
Purpose: Efficacy, tolerability and safety of the novel preservative-free prostaglandin tafluprost $0.0015 \%$ were investigated for the treatment of patients with glaucoma or ocular hypertension in a clinical setting.

Patients and methods: Data were collected in a non-interventional, prospective, multi-center, observational, open label study. 118 patients were treated with a prostaglandin analog (PGA) monotherapy (preserved formulations of latanoprost, travoprost or bimatoprost) prior to baseline. Intraocular pressure (IOP) readings were recorded for each eye at baseline (previous therapy), 4-6 weeks, and 12 weeks after changing medical treatment to preservative-free tafluprost once-daily. We analyzed the change in IOP over the study period for all patients as well as for a subgroup of patients with prior PGA monotherapy. Subjective symptoms and objective ocular signs were determined. Comfort was measured using a 4 step scale. All adverse events were recorded. Paired $t$-tests were conducted to compare IOP values at baseline to IOP values after treatment with tafluprost $0.0015 \%$. Bowker's test of symmetry was used for statistical evaluation of changes of clinical signs (hyperemia).

Results: In total 118 patients were eligible for evaluation. In these patients with prior PGA monotherapy ( $\mathrm{n}=118$ ) IOP decreased significantly from $16.2 \pm 4.3 \mathrm{~mm} \mathrm{Hg}$ (95\% CI: 0.55$)$ at treated baseline to $14.8 \pm 3.2 \mathrm{~mm} \mathrm{Hg}(95 \% \mathrm{CI}: 0.43 ; P<0.001)$ at final visit on tafluprost. In a subset of patients with prior latanoprost monotherapy $(\mathrm{n}=68)$ mean IOP at baseline $( \pm \mathrm{SD})$ was reduced from $16.2 \pm 4.6 \mathrm{~mm} \mathrm{Hg}(95 \% \mathrm{CI}: 0.77) 14.8 \pm 3.1 \mathrm{~mm} \mathrm{Hg}$ at final visit (95\% CI: $0.54, P<0.001)$, in patients with prior travoprost monotherapy $(\mathrm{n}=32)$ from $16.2 \pm 4.3 \mathrm{~mm} \mathrm{Hg}(95 \% \mathrm{CI}: 1.05)$ to $14.9 \pm 3.3 \mathrm{~mm} \mathrm{Hg}(95 \% \mathrm{CI}: 0.91 ; P<0.05)$ and in patients with prior bimatoprost monotherapy $(\mathrm{n}=18)$ from $16.4 \pm 3.5 \mathrm{~mm} \mathrm{Hg}(95 \% \mathrm{CI}: 1.14)$ to $15.0 \pm 3.3 \mathrm{~mm} \mathrm{Hg}(95 \% \mathrm{CI}: 1.14 ; P=0.252)$. Both, objective clinical signs and subjective symptoms improved after changing medication to preservative-free tafluprost until final visit. The number of patients with moderate and severe hyperemia decreased from $51(43.2 \%)$ at baseline to $2(1.9 \%)$ at final visit.

Conclusion: Preservative-free tafluprost $0.0015 \%$ was effective, well tolerated and safe. IOP was controlled effectively and ocular symptoms and clinical signs were improved after changing medication to a monotherapy with preservative-free tafluprost in patients previously treated with a preserved latanoprost, travoprost or bimatoprost monotherapy.

Keywords: tafluprost, intraocular pressure, prostaglandin-analogs, preservatives, local tolerability hyperemia

\section{Introduction}

Glaucoma is the second leading cause of preventable blindness worldwide. In 2010 worldwide approximately 60.5 million people are suffering primary open angle 
glaucoma (POAG) and angle closure glaucoma (ACG). This number is estimated to increase to 79.6 million by $2020 .^{1}$ Increased intraocular pressure (IOP) is considered to be the most important but modifiable risk factor. ${ }^{2-4}$ Worldwide, $^{-}$ prostaglandin analogs (PGAs) have become the major therapeutic class for medical treatment of glaucoma because of their efficacy and generally well tolerated systemic safety profile. ${ }^{5}$ Tafluprost is a novel PGA that has been approved for ophthalmic use in a number of markets worldwide. The drug is currently marketed under the brand names: Taflotan ${ }^{+}$ and Taflotan ${ }^{+}$sine and Tapros ${ }^{\dagger}$, by Santen Pharmaceutical Co. LTD, Japan and as Saflutan ${ }^{\dagger \dagger}$ by Merck \& Co , Inc. Tafluprost is highly selective for the prostaglandin FP-receptor. ${ }^{6,7}$ PGAs including Tafluprost have a strong, sustained and stable IOP-lowering effect with few systemic side effects. In clinical studies the drug lowered IOP effectively and was generally well tolerated. ${ }^{8-10}$ Unfortunately, PGAs may induce local adverse events, including conjunctival hyperemia, iris and periocular skin pigmentation and eyelash growth. ${ }^{9,11}$ Hyperemia is the most common local adverse reaction to PGAs. Furthermore this local adverse event seems to be dose-dependent. ${ }^{12,13}$ Tafluprost is commercially available in a low concentration of the active ingredient of $0.0015 \%$. Furthermore, among all widely used PGAs, tafluprost is the first and only preparation that is available in a preservative-free formulation. This may be important because special attention has been paid to the cytotoxicity of benzalkonium chloride (BAK), which is widely used in glaucoma preparations as a preservative. BAK is pro-apoptotic, pro-inflammatory and causes a damage of the tear film by emulsification of the lipid layer. ${ }^{14-16}$ A complete loss of conjunctival goblet cells was also reported in different studies. ${ }^{17,18}$ Other clinical studies demonstrate major differences with respect to subjective symptoms, local tolerability and objective clinical signs after the use of preserved and preservative-free glaucoma medications. ${ }^{19-21}$

The overall results of this observational study have already been published. ${ }^{22}$ The purpose of this post-hoc analysis was to assess efficacy, tolerability and safety of preservative-free tafluprost in a subset of patients that were switched from a prior monotherapy with preserved PGAs to a monotherapy with preservative-free tafluprost $0.0015 \%$ in a routine clinical setting.

\footnotetext{
${ }^{+}$Taflotan ${ }^{\circledR}$, Taflotan ${ }^{\circledR}$ sine,

${ }^{\dagger}$ Tapros $^{\mathrm{TM}}$ are registered trademarks of Santen Pharmaceutical Co., Ltd, Osaka, Japan.

${ }^{\dagger}$ Saflutan ${ }^{\circledR}$ is a registered trademarks of Merck \& Co., Inc.
}

\section{Material and methods}

\section{Study design}

This was a non-interventional, observational, open-label, nonrandomized multi-center study, that was conducted between October 2008 and April 2009 in 75 centers in Germany. The study treatment was based on the decision of the physician only, regardless of study participation and treatment use. German law does not require informed consent for this type of non-interventional observational study. Patients previously diagnosed with glaucoma or ocular hypertension who required a change of medication, an add-on therapy or who were naïve to medical treatment were followed for 12 weeks after changing medication to, or initiation of medical therapy with, the preservative-free formulation of tafluprost $0.0015 \%$ once-daily. The primary objective of this study was to evaluate the change of mean IOP from baseline to final visit. Secondary objectives were to evaluate the change of clinical signs and subjective symptoms from baseline to final visit.

\section{Patients}

The study included patients with different types of glaucoma and ocular hypertension, primarily those with tolerability issues and insufficient IOP control with prior medical therapy.

\section{Measurements and statistical analysis}

Using an internet- based standardized data collection format, participating ophthalmologists provided anonymous patient data. The switch was done at the physician's discretion, and their reasons for recommending the new medication were collected by providing multiple categories (ocular signs and symptoms, lowering of IOP not sufficient, contraindication, systemic intolerability, progression of glaucomatous defects, tachyphylaxis, others). Demographics, information about prior treatments and IOP readings were recorded. Due to the observational character of the study no instructions were made to the study participants concerning the time of IOP measurements during the day and the time-point to administer the medication during the day (evening or morning dose). The presence of subjective symptoms (burning, foreign body sensation, itching, irritation, stinging, tearing, dryness) and clinical signs (hyperemia, corneal staining, blepharitis) were recorded subjectively by the physician using a 4-point scale (none, mild, moderate, severe) at the initial visit. Symptoms at final visit (week 12) were compared to baseline by the patient, and clinical signs were recorded by the physician. IOP measurements were made using Goldman applanation tonometry for each eye, at the slitlamp in a sitting position, at baseline (run-in on prior treatment or start of medical therapy), 4 to 
6 weeks and 12 weeks after changing treatment to preservative-free tafluprost $0.0015 \%$. Glaucomatous damage was defined by using automatic perimetry, ophthalmoscopy and/ or optic nerve head/fundus imaging techniques. Paired $t$-tests were conducted to compare IOP values at baseline to IOP values after treatment with tafluprost $0.0015 \%$. Bowker's test of symmetry was used for statistical evaluation of changes of clinical signs (hyperemia). All adverse reactions were recorded by the physicians.

\section{Results}

\section{Patient demographics and prior therapy}

In 118 patients, medical treatment was changed from a prior PGA monotherapy at baseline to preservative-free tafluprost $0.0015 \%$. The results from this subset of patients are reported here. The majority of patients in the PGA-subgroup were female $(\mathrm{n}=82 ; 69.5 \%)$. Primary open angle glaucoma (POAG) was the most common diagnosis $(n=93 ; 78.8 \%)$ followed by ocular hypertension $(\mathrm{OH})(\mathrm{n}=14 ; 11.9 \%)$, normal tension glaucoma $(\mathrm{NTG})(\mathrm{n}=10 ; 8.5 \%)$ and exfoliative glaucoma $(\mathrm{PEX})(\mathrm{n}=1$; $0.8 \%$ ). At baseline prior to change of medication to a monotherapy with preservative-free tafluprost, 68 patients $(57.6 \%)$ were treated with latanoprost, 32 patients $(27.1 \%)$ with travoprost and 18 patients $(15.3 \%)$ with bimatoprost (Table 1$)$.

\section{Reasons for changing medication}

Subjective symptoms and clinical signs were the most important reasons for changing medical therapy $(n=72$ patients; $61.0 \%$ ). Prior medication was changed for 24 patients $(20.3 \%)$ due to efficacy reasons (Figure 1).

\section{Effect on IOP}

Overall mean IOP $( \pm \mathrm{SD})$ was $16.2 \pm 4.3 \mathrm{~mm} \mathrm{Hg}$ (95\% CI: 0.55) at treated baseline. Four to 6 weeks after

Table I Patient demographics, diagnoses and medical treatment at baseline $(\mathrm{n}=118)$

\begin{tabular}{ll}
\hline Age (mean [range]) (years) & $63.6[32-92]$ \\
Gender (male/female) & $36 / 82$ \\
Diagnoses & \\
- Ocular hypertension & $14(11.9 \%)$ \\
- Primary open angle glaucoma & $93(78.8 \%)$ \\
- Normal tension glaucoma & $10(8.5 \%)$ \\
- Exfoliative glaucoma & $1(0.8 \%)$ \\
Glaucoma since years (mean [range]) & $6.7[1-22]$ \\
Prior PGA treatment (monotherapy) & \\
- Latanoprost & $68(57.6 \%)$ \\
- Travoprost & $32(27.1 \%)$ \\
- Bimatoprost & $18(15.3 \%)$ \\
\hline
\end{tabular}

Abbreviation: PGA, prostaglandin analog. changing medication, overall mean IOP was reduced to $15.0 \pm 3.2 \mathrm{~mm} \mathrm{Hg}(95 \% \mathrm{CI}: 0.43)$, and after 12 weeks to $14.8 \pm 3.2 \mathrm{~mm} \mathrm{Hg}(95 \% \mathrm{CI}: 0.43)$ (Figure 2). This IOP reduction is equivalent to $8.4 \%$ and $8.6 \%$ from treated baseline, respectively. At both 4 to 6 weeks and 12 weeks, overall treated IOP values were significantly lower than baseline values $(P<0.001)$. A reduction of mean IOP was also achieved for all different PGA compounds: In patients with prior latanoprost monotherapy $(n=68)$ mean IOP at baseline $( \pm \mathrm{SD})$ was reduced from $16.2 \pm 4.6 \mathrm{~mm} \mathrm{Hg}(95 \%$ CI: 0.77 ) to $14.8 \pm 3.1 \mathrm{~mm} \mathrm{Hg}$ at final visit (95\% CI: 0.54 ; $P<0.001)$; in patients with prior travoprost monotherapy $(\mathrm{n}=32)$ from $16.2 \pm 4.3 \mathrm{~mm} \mathrm{Hg}(95 \% \mathrm{CI}: 1.05)$ to $14.9 \pm 3.3 \mathrm{~mm} \mathrm{Hg}$ (95\% CI: $0.91 ; P<0.05$ ); and in patients with prior bimatoprost monotherapy $(\mathrm{n}=18)$ from $16.4 \pm 3.5 \mathrm{~mm} \mathrm{Hg}(95 \% \mathrm{CI}: 1.14)$ to $15.0 \pm 3.3 \mathrm{~mm} \mathrm{Hg}$ (95\% CI: $1.14 ; P=0.252$ ). In all patients with prior PGA monotherapy, IOP at final visit compared to baseline IOP was lower in 109 eyes (46.2\%), equal in 51 eyes (21.6\%) and higher in 76 eyes (32.2\%) (Figure 3). In all patients with prior PGA monotherapy, preservative-free tafluprost $0.0015 \%$ provided IOP-values of $\leq 18 \mathrm{~mm} \mathrm{Hg}$ for $83.1 \%, \leq 16 \mathrm{~mm}$ $\mathrm{Hg}$ for $68.6 \%, \leq 14 \mathrm{~mm} \mathrm{Hg}$ for $51.7 \%$ and $\leq 12 \mathrm{~mm} \mathrm{Hg}$ for $28.0 \%$ of all eyes. In the subset of patients $(n=24)$ who were switched from prior PGA monotherapy to preservative-free tafluprost due to efficacy reasons mean IOP was lowered significantly by $-3.9 \mathrm{~mm} \mathrm{Hg}(P<0.001)$ compared to baseline. Individual IOP's in those patients were lower at final visit compared to baseline in 28 eyes $(58.2 \%)$, stayed the same in 12 eyes $(25.0 \%)$ and were higher compared to baseline in 6 eyes $(16.7 \%)$. In contrast IOP in two subsets of patients switched due to ocular signs $(\mathrm{n}=31)$ and due to subjective symptoms $(n=41)$ a smaller effect on IOP reduction was observed (Table 2).

\section{Clinical signs and ocular symptoms}

Clinical signs also improved by the final examination (12 weeks after changing medical treatment). The frequency and severity of hyperemia was reduced over the 3 month treatment period. In all patients with prior PGA monotherapy the percentage of patients without any signs of hyperemia increased from $35.6 \%(\mathrm{n}=42)$ at baseline prior to changing medication to $87.7 \%(\mathrm{n}=93)(P<$ $0.001)$. In addition, no severe hyperemia was observed at final visit 12 weeks after changing medication to preservative-free tafluprost (Figure 4). At baseline prior to change of medication, burning, foreign body sensation, itching, irritation, stinging, tearing and dryness 


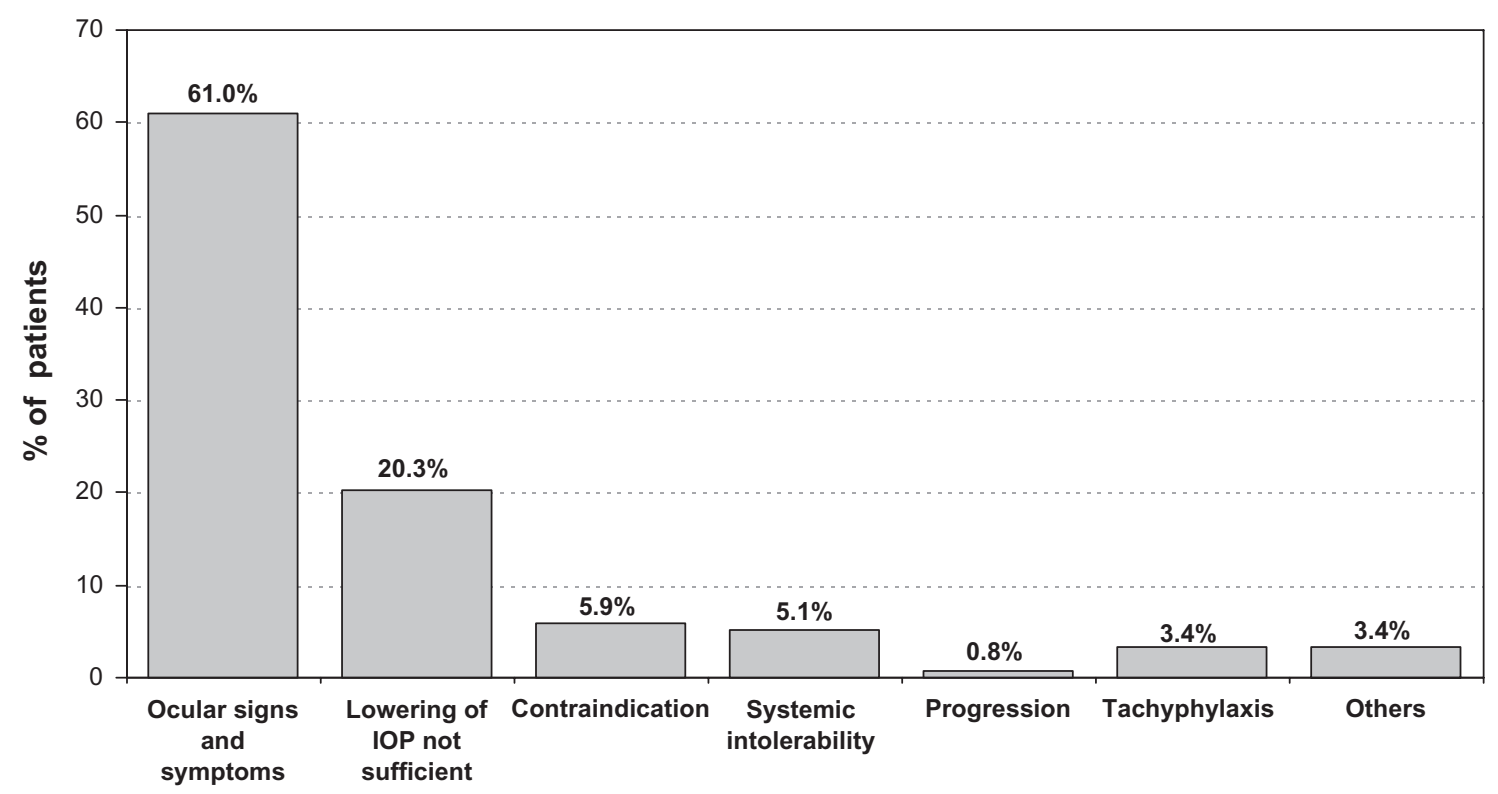

Figure I Reasons for changing medication for patients with prior PGA monotherapy. Abbreviations: IOP, intraocular pressure; PGA, prostaglandin analog.

were reported by $55.9 \%, 36.5 \%, 33.1 \%, 58.5 \%, 16.9 \%$, $27.1 \%$ and $21.2 \%$ of patients respectively. These subjective symptoms improved by the final examination compared to baseline (Figure 5).

\section{Safety and terminations of treatment}

Few adverse reactions were associated with the use of preservative-free tafluprost. One hundred and six patients completed the study and continued with a monotherapy with preservative-free tafluprost. Three patients $(2.5 \%)$ terminated the treatment due to a lack of efficacy, 2 patients due to conjunctival hyperemia (1.7\%), 3 patients $(2.5 \%)$ due to handling issues and preference, 3 patients $(2.5 \%)$ due to tolerability issues (burning, hyperemia, stinging, dryness) and 1 patient $(0.8 \%)$ due to subjective malaise.

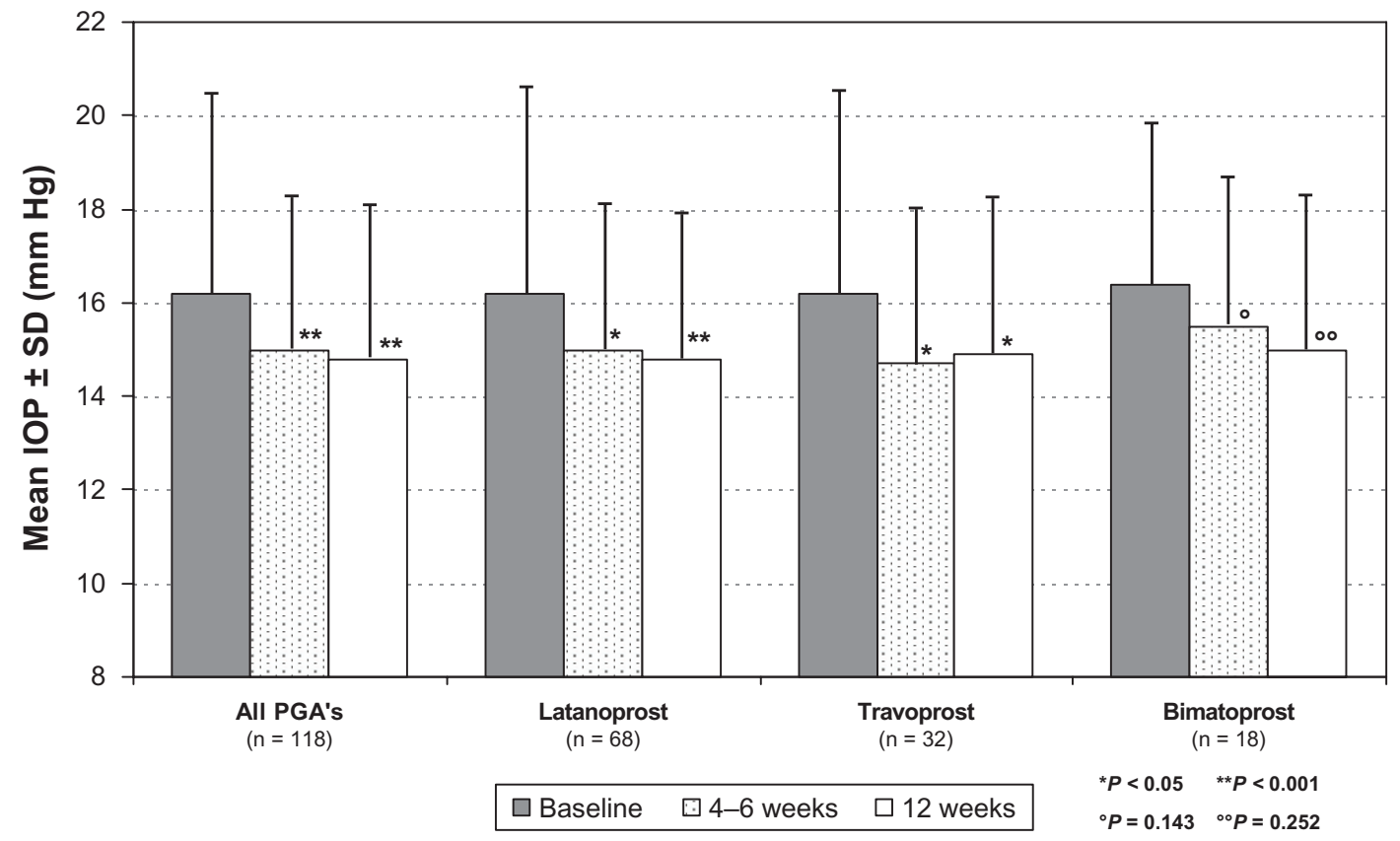

Figure 2 Mean IOP $( \pm S D)$ in all patients $(n=118)$ treated with prior PGA monotherapy and for the different PGA compounds. Abbreviations: IOP, intraocular pressure; PGA, prostaglandin analog; SD, standard deviation. 


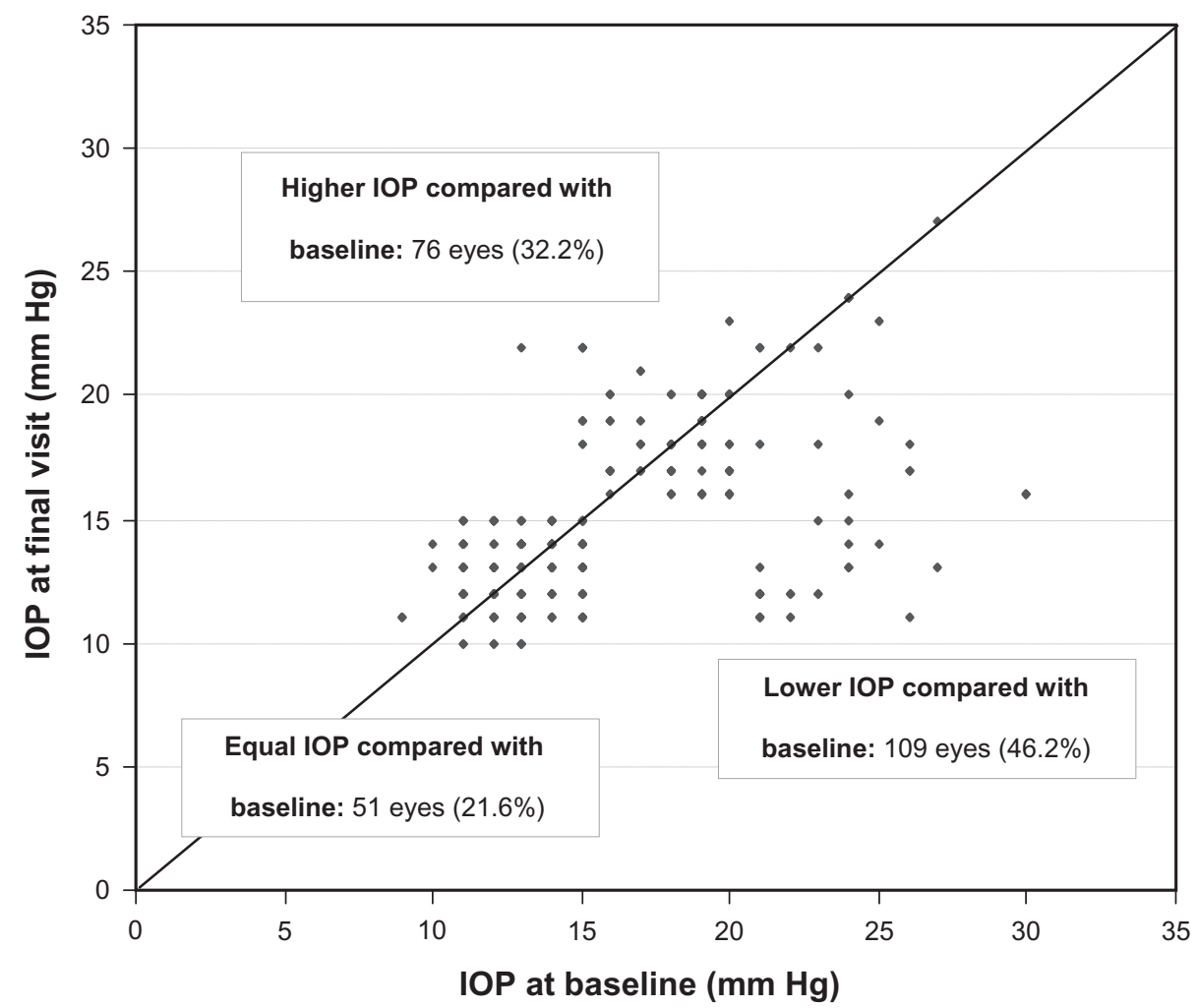

Figure 3 IOP in all individual patients $(n=118 ; 236$ eyes) treated with prior PGA monotherapy at baseline versus final visit after change of medication to a monotherapy with preservative-free tafluprost $0.0015 \%$.

Abbreviations: IOP, intraocular pressure; PGA, prostaglandin analog.

\section{Discussion}

The results of this non-interventional, open-label, multicentre observational study demonstrate that preservative-free tafluprost can achieve good IOP control in patients switched from a prior PGA monotherapy due to poor IOP control and/or tolerability issues. After change of medication mean IOP decreased significantly until final visit by $1.4 \mathrm{~mm} \mathrm{Hg}$ (8.7\%). There were two main reasons for switching therapy from prior PGA monotherapy to preservative-free tafluprost:

Table 2 Differences in mean IOP between baseline (prior PGA therapy) and final visit 12 weeks after changing medication to preservative-free tafluprost stratified by reasons for change of medication

\begin{tabular}{llll}
\hline $\begin{array}{l}\text { Reason for changing } \\
\text { medication }\end{array}$ & $\begin{array}{l}\text { Number } \\
\text { of patients } \\
\text { (baseline visit) }\end{array}$ & $\begin{array}{l}\Delta \text { IOP } \\
\mathbf{( m m ~ H g )}\end{array}$ & P-value** \\
\hline $\begin{array}{l}\text { IOP lowering effect } \\
\text { not sufficient or target }\end{array}$ & 24 & -3.9 & $<0.00 \mathrm{I}$ \\
$\begin{array}{l}\text { pressure not achieved } \\
\text { Ocular signs }\end{array}$ & $3 \mathrm{I}$ & -1.4 & 0.009 \\
Subjective Symptoms & $4 \mathrm{I}$ & -0.1 & $0.76 \mathrm{I}$ \\
\hline
\end{tabular}

Note: **LOCF-analysis, t-test for paired samples.

Abbreviations: $\triangle \mathrm{IOP}, \mathrm{IOP}$ at final visit minus IOP at baseline; IOP, intraocular pressure; PGA, prostaglandin analog.
Ocular symptoms and clinical signs like hyperemia accounted for $61.0 \%$ and a lack of efficacy of prior medication for $20.3 \%$ of changes of treatment. This may explain why the mean (treated) IOP at baseline was relatively low, $16.2 \pm 4.3 \mathrm{~mm}$ $\mathrm{Hg}$. Interestingly, regardless of low mean baseline IOP, lower IOP-values were achieved 12 weeks after changing medication from prior PGA monotherapy in a high proportion of patients: IOP was lower compared to baseline IOP in 109 eyes $(46.2 \%)$, remained at the same level in 51 eyes $(21.6 \%)$ and was higher in 76 eyes (32.2\%). In patients switched due to a lack of efficacy of prior PGA monotherapy significant lower mean IOP-values were achieved $(-3.9 \mathrm{~mm} \mathrm{Hg}$ versus treated baseline; $P<0.001)$. Lower individual IOP's were achieved in $58.2 \%$ of all eyes of these patients. These findings suggest that it may be worthwhile to consider a change of medication to preservative-free tafluprost for patients treated with preserved PGAs with insufficient IOP response. The efficacy of preservative-free tafluprost was compared to other prostaglandins in various studies. ${ }^{9,23-26}$ In a study comparing efficacy and safety of tafluprost $0.0015 \%$ and latanoprost $0.005 \%$, Uusitalo et $\mathrm{al}^{9}$ found a decrease of mean IOP versus. baseline of $-7.1 \mathrm{~mm} \mathrm{Hg}$ in the tafluprost treatment group $(-29.1 \%)$ compared with 


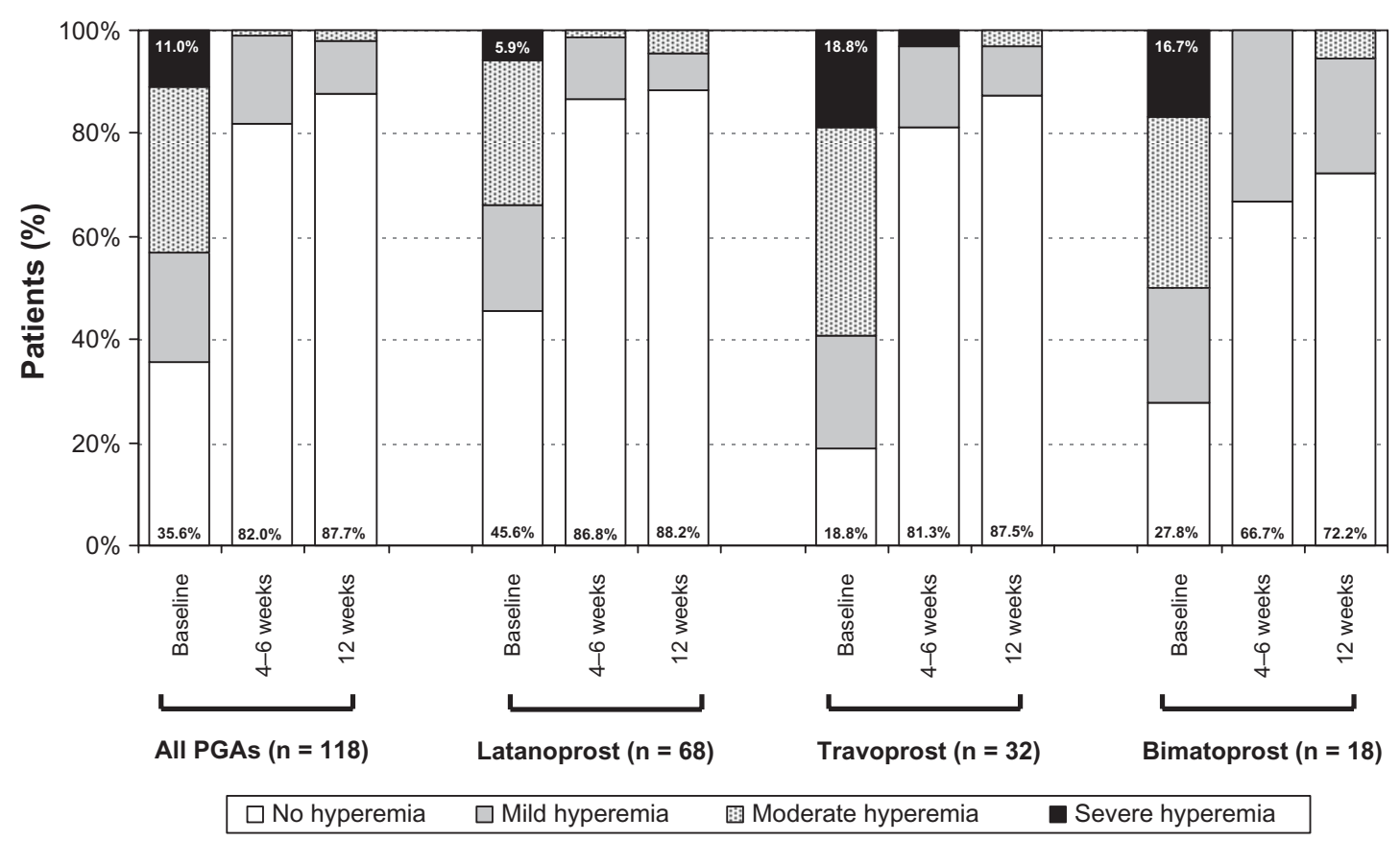

Figure 4 Development of conjunctival hyperemia after change of medication from prior PGA monotherapy to a monotherapy with preservative-free tafluprost 0.00 I $5 \%$. Abbreviation: PGA, prostaglandin analog.

$-7.7 \mathrm{~mm} \mathrm{Hg}(-32.2 \%)$ in the latanoprost treatment group. Non-inferiority was shown in this study with ANOVA and almost reached with ANCOVA. Compared to these results our study design was different: Firstly, patients with prior PGA treatment were switched to preservative-free tafluprost without any washout-period. Secondly, a high proportion of patients were switched to preservative-free tafluprost due to tolerability (subjective symptoms and/or clinical signs such as hyperemia) and/or efficacy issues. The study design of the present study may therefore better reflect the treatment

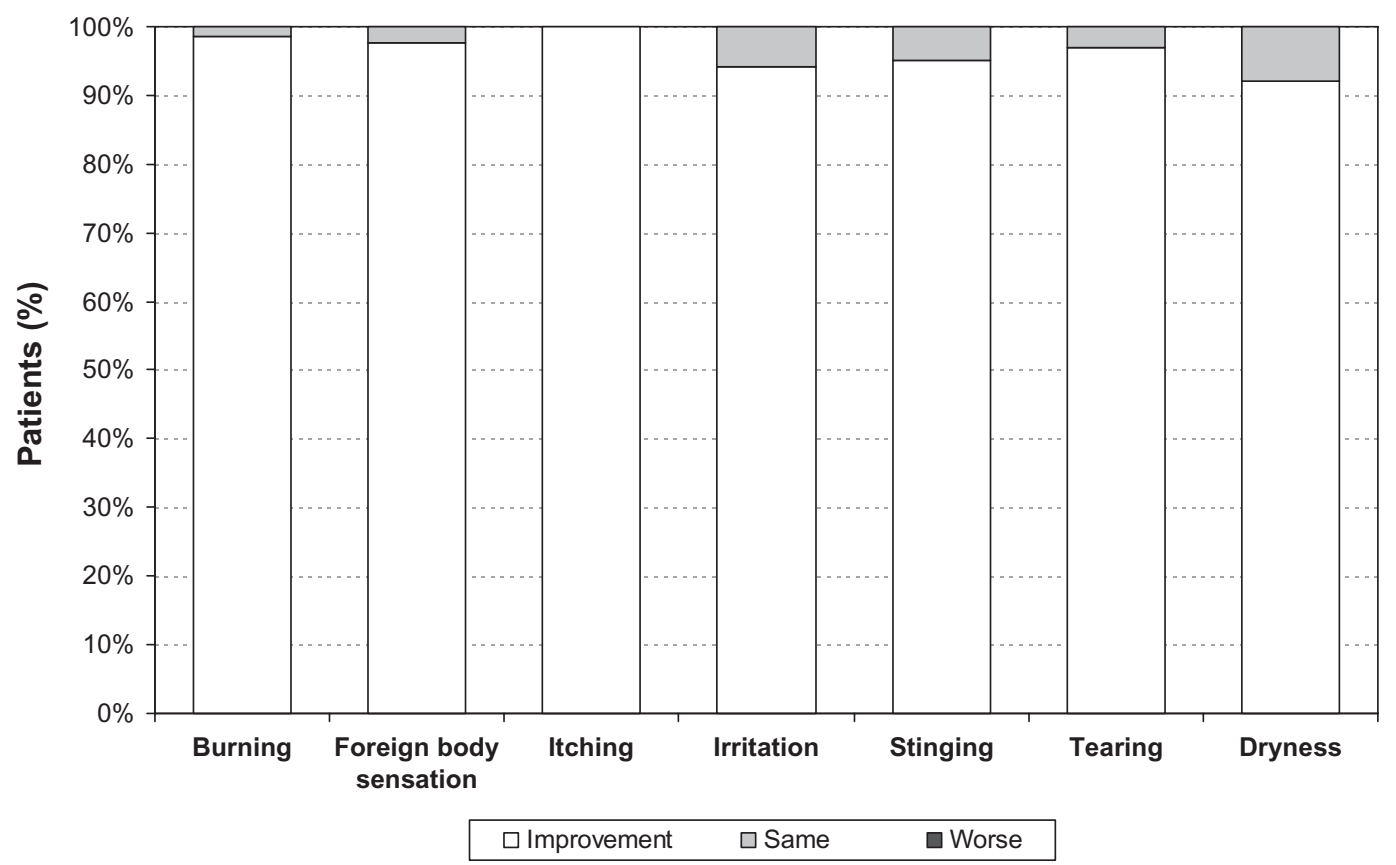

Figure 5 Development of subjective symptoms after change of medication from prior PGA monotherapy to a monotherapy with preservative-free tafluprost 0.00 I $5 \%$. Abbreviation: PGA, prostaglandin analog. 
algorithms in day to day practice and also explain the additional decrease in mean IOP seen in this study. In a phase I study with formulations containing 0.0025 and $0.005 \%$ tafluprost, IOP was lowered effectively with both concentrations of tafluprost. ${ }^{24}$ The higher concentration of tafluprost provided a significantly greater IOP reduction compared to latanoprost for most time-points. However, this study was performed in healthy male volunteers over a relatively short period of time of 7 days. Another study comparing efficacy and tolerability of tafluprost and travoprost found a difference in 12-hour mean IOP of $0.6 \mathrm{~mm} \mathrm{Hg}$ in favor of travoprost. ${ }^{25}$ However, the formulation of tafluprost used in this study was not detailed. Due to the double-blind character of this study it might be assumed that the preserved-formulation of tafluprost was used, which might explain the different findings, especially related to the development of clinical signs such as hyperemia compared to the present study. The presence of the preservative BAK seems to have no influence on the efficacy of tafluprost: in a study comparing the effect of a BAK-preserved and a preservative-free formulation of tafluprost, the formulations did not differ significantly in their IOP lowering effect. ${ }^{26}$ Even a small change in IOP seems to be important with respect to visual field and optic nerve preservation: every $1 \mathrm{~mm} \mathrm{Hg}$ was found to be equivalent to an increased risk of glaucoma progression of $10 \%$ to $19 \%$. 3,27

Local tolerability and clinical signs are other important factors in patients with chronic diseases such as glaucoma. Two aspects are important in this context: firstly, a large body of evidence exists showing that the long-term use of topical drugs containing BAK as a preservative may induce changes in the ocular surface, tear film instability, epithelial apoptosis, conjunctival inflammation and loss of goblet cells. ${ }^{14-18}$ Secondly, there is evidence that the prevalence of ocular surface disorders is high in glaucoma patients: in a study by Leung $59 \%$ of patients with open-angle glaucoma or ocular hypertension reported dry eye symptoms in at least 1 eye..$^{28}$ In another study by Erb, dry eye syndrome was diagnosed in $52.6 \%$ of glaucoma patients. ${ }^{29}$ In both studies, the occurrence of dry eye syndrome increased with the number of preservative- containing antiglaucoma drugs used.

After switching from preserved PGA monotherapy to preservative-free tafluprost, subjective symptoms and clinical signs such as hyperemia improved significantly $(P<0.001)$ in most patients. Consistent with previous reports our results confirm that patients with irritation of the ocular surface, subjective symptoms and clinical changes of the eye surface, such as hyperemia, may benefit from a change of medication to the preservative-free formulation of tafluprost. ${ }^{30}$ During the course of this observational study hyperemia which was present in a high proportion of patients at baseline decreased significantly: No patient showed a severe hyperemia at the end of the study-period. In $87.7 \%$ of patients with prior PGA-monotherapy treatment no conjunctival hyperemia was present after 12 weeks. Regarding local tolerability of glaucoma medications, clinical studies show that a high proportion of glaucoma patients develop symptoms like burning and stinging, foreign body sensation, dry eye and irritation of the ocular surface. Consistent with prior reports ${ }^{19,20}$ that these symptoms were reported significantly less often in patients receiving preservativefree preparations, subjective symptoms improved until final visit in this subset of patients treated with prior PGA monotherapy. Preservative-free tafluprost was generally well tolerated and safe: 106 patients $(89.8 \%)$ remained on a monotherapy with preservative-free tafluprost after the 12 weeks of treatment.

This observational study is limited by its open-label design. Due to its observational nature, the study did not reveal any causal relationships. The observed IOP reduction after switching might be ascribed not only to the improvement of subjective symptoms and clinical signs and thus a better compliance, but also to the patient population at baseline itself. Also, regression to the mean cannot be ruled out in the current study design since a control group was not used. Further studies with higher numbers of patients are necessary to determine what aspects of preservative-free therapy with tafluprost account for the observed treatment effects.

\section{Conclusion}

In this observational study, preservative-free tafluprost $0.0015 \%$ was effective and generally well tolerated in patients with prior PGA monotherapy. Preservative-free tafluprost provided further IOP reduction in patients with poor IOP control and/or poor tolerance of their medication prior to tafluprost use. Mean IOP decreased slightly after change of medication to preservative-free tafluprost. In patients with prior latanoprost monotherapy $(n=68)$ mean IOP at baseline $( \pm \mathrm{SD})$ was reduced from $16.2 \pm 4.6 \mathrm{~mm} \mathrm{Hg}$ to $14.8 \pm 3.1 \mathrm{~mm} \mathrm{Hg}$ at final visit $(P<0.001)$; in patients with prior travoprost monotherapy $(\mathrm{n}=32)$ from $16.2 \pm 4.3 \mathrm{~mm} \mathrm{Hg}$ to $14.9 \pm 3.3 \mathrm{~mm} \mathrm{Hg}(P<0.05)$; and in patients with prior bimatoprost monotherapy $(\mathrm{n}=18)$ from $16.4 \pm 3.5 \mathrm{~mm} \mathrm{Hg}$ to $15.0 \pm 3.3 \mathrm{~mm} \mathrm{Hg}(P=0.252)$. Change of medication to 
preservative-free tafluprost may be beneficial especially for patients with objective clinical signs and subjective symptoms of ocular surface disease: conjunctival hyperemia which was present at baseline in $64.4 \%$ of patients treated with a PGA monotherapy decreased significantly $(P<0.001)$ during the 12 week treatment period and was found in only $12.3 \%$ of patients at final visit. Our data further suggest that a change of medical therapy to preservative-free tafluprost in patients with prior preserved PGA monotherapy may be especially beneficial for patients with subjective ocular symptoms and/or clinical signs and also for patients who are not responding adequately to a prior PGA monotherapy treatment regimen.

\section{Acknowledgments/disclosure}

This study was financially supported by Santen Oy, Tampere, Finland. A Hommer is a consultant/advisor and speaker for Santen Oy. F Kimmich is a consultant for Santen Oy. Medical writing, data management and statistical analysis of the present study were done by eyecons (F Kimmich) with financial support from Santen Oy.

\section{References}

1. Quigley HA, Broman AT. The number of people with glaucoma worldwide in 2010 and 2020. Br J Ophthalmol. 2006;90(3):262-267.

2. Kass MA, Heuer DK, Higginbotham EJ, et al. The Ocular Hypertension Treatment Study: a randomized trial determines that topical ocular hypotensive medication delays or prevents the onset of primary openangle glaucoma. Arch Ophthalmol. 2002;120(6):701-713.

3. Heijl A, Leske MC, Bengtsson B, et al. Reduction of intraocular pressure and glaucoma progression: results from the Early Manifest Glaucoma Trial. Arch Ophthalmol. 2002;120(10):1268-1279.

4. AGIS Investigators. The Advanced Glaucoma Intervention Study (AGIS):7. The relationship between control of intraocular pressure and visual field deterioration. Am J Ophthalmol. 2000;130(4):429-440.

5. Bean GW, Camras CB. Commercially available prostaglandin analogs for the reduction of intraocular pressure: similarities and differences. Surv Ophthalmol. 2008;53 Suppl 1:S69-S84.

6. Nakajima T, Matsugi T, Goto W, et al. New fluoroprostaglandin F(2alpha) derivatives with prostanoid FP-receptor agonistic activities as potent ocular hypotensive agents. Biol Pharm Bull. 2003;26(12):1691-1695.

7. Takagi Y, Nakajima T, Shimazak A, et al. Pharmacological characteristics of AFP-168 (tafluprost), a new prostanoid FP receptor agonist, as an ocular hypotensive drug. Exp Eye Res. 2004;78(4): 767-776.

8. Hommer A. A review of preserved and preservative-free prostaglandin analogues for the treatment of open-angle glaucoma and ocular hypertension. Drugs Today. 2010;46(6):409-416.

9. Uusitalo H, Pillunat LE, Ropo A. Efficacy and safety of tafluprost $0.0015 \%$ versus latanoprost $0.005 \%$ eye drops in open-angle glaucoma and ocular hypertension: 24-month results of a randomized, doublemasked phase III study. Acta Ophthalmol. 2010;88(1):12-19.

10. Traverso CE, Ropo A, Papadia M, Uusitalo H. A phase II study on the duration and stability of the intraocular pressure-lowering effect and tolerability of Tafluprost compared with latanoprost. J Ocul Pharmacol Ther. 2010;26(1):97-104.
11. Honrubia F, García-Sánchez J, Polo V, de la Cassa JM, Soto J. Conjunctival hyperaemia with the use of latanoprost versus other prostaglandin analogues in patients with ocular hypertension or glaucoma: a meta-analysis of randomised clinical trials. $\mathrm{Br} J$ Ophthalmol. 2009;93(3):316-321.

12. Sutton A, Gouws P, Ropo A. Tafluprost, a new potent prostanoid receptor agonist: a dose-response study on pharmacodynamics and tolerability in healthy volunteers. Int J Clin Pharmacol Ther. 2008;46(8): 400-406.

13. Katz LJ, Cohen JS, Batoosingh AL, Felix C, Shu V, Schiffman RM. Twelve-month, randomized, controlled trial of bimatoprost $0.01 \%$, $0.0125 \%$, and $0.03 \%$ in patients with glaucoma or ocular hypertension. Am J Ophthalmol. 2010;149(4):661-671.

14. Baudouin C. Side effects of antiglaucomatous drugs on the ocular surface. Curr Opin Ophthalmol. 1996;7(2):80-86.

15. Vaede D, Baudouin C, Warnet JM, Brignole-Baudouin F. [Preservatives in eye drops: toward awareness of their toxicity] [Article in French]. J Fr Ophthalmol. 2010;33(7):505-524.

16. Brasnu E, Brignole-Baudouin F, Riancho L, Guenin JM, Warnet JM, Baudouin C. In vitro effects of preservative-free tafluprost and preserved latanoprost, travoprost, and bimatoprost in a conjunctival epithelial cell line. Curr Eye Res. 2008;33(4):303-312.

17. Liang H, Baudouin C, Pauly A, Brignole-Baudouin F. Conjunctival and corneal reactions in rabbits following short- and repeated exposure to preservative-free tafluprost, commercially available latanoprost and $0.02 \%$ benzalkonium chloride. $\mathrm{Br} J$ Ophthalmol. 2008 Sep;92(9):1275-1282.

18. Kahook MY, Noecker R. Quantitative analysis of conjunctival goblet cells after chronic application of topical drops. Adv Ther. 2008;25(8):743-751.

19. Jaenen N, Baudouin C, Pouliquen P, Manni G, Figueiredo A, Zeyen T. Ocular symptoms and signs with preserved and preservative-free glaucoma medications. Eur J Ophthalmol. 2007;17(3):341-349.

20. Pisella PJ, Pouliquen P, Baudouin C. Prevalence of ocular symptoms and signs with preserved and preservative free glaucoma medication. Br J Ophthalmol. 2002;86(4):418-423.

21. Nordmann JP, Auzanneau N, Ricard S, Berdeaux G. Vision related quality of life and topical glaucoma treatment side effects. Health Qual Life Outcomes. 2003;10(1):75.

22. Hommer A, Ramez MO, Burchert M, Kimmich F. IOP-lowering efficacy and tolerability of preservative-free tafluprost $0.0015 \%$ among patients with ocular hypertension or glaucoma. Curr Med Res Opin. 2010;26(8):1905-1913.

23. Uusitalo H, Kaarniranta, K, Ropo A. Pharmacokinetics, efficacy and safety profiles of preserved and preservative-free tafluprost in healthy volunteers. Acta Ophthalmol Suppl (Oxf). 2008;242:7-13.

24. Sutton A, Gilvarry A, Ropo A. A comparative, placebo-controlled study of prostanoid fluoroprostaglandin-receptor agonists tafluprost and latanoprost in healthy males. J Ocul Pharmacol Ther. 2007;23(4):359-365.

25. Schnober D, Hofmann G, Maier, Scherzer ML, Oqundele AB, Jasek MC. Diurnal IOP-lowering efficacy and safety of travoprost $0.004 \%$ compared to tafluprost $0.0015 \%$ in patients with primary openangle glaucoma or ocular hypertension. Clin Ophthalmol. 2010;8(4): 1459-1463.

26. Hamacher T, Airaksinen J, Saarela, Liinamaa MJ, Richetr U, Ropo A. Efficacy and safety levels of preserved and preservative-free tafluprost are equivalent in patients with glaucoma or ocular hypertension: results from a pharmacodynamics analysis. Acta Ophthalmol Suppl (Oxf). 2008;242:14-19.

27. Chauhan BC, Mikelberg FS, Balazi AG, et al. Canadian Glaucoma Study: 2. risk factors for the progression of open-angle glaucoma. Arch Ophthalmol. 2008;126(8):1030-1036.

28. Leung EW, Medeiros FA, Weinreb RN. Prevalence of ocular surface disease in glaucoma patients. J Glaucoma. 2008;17(5): $350-355$. 
29. Erb C, Gast U, Schremmer D. German register for glaucoma patients with dry eye. I. Basic outcome with respect to dry eye. Graefes Arch Clin Exp Ophthalmol. 2008;246(11):1593-1601.
30. Uusitalo H, Chen E, Pfeiffer N, et al. Switching from a preserved to a preservative-free prostaglandin preparation in topical glaucoma medication. Acta Ophthalmol. 2010;88(3):329-336.
Clinical Ophthalmology

\section{Publish your work in this journal}

Clinical Ophthalmology is an international, peer-reviewed journal covering all subspecialties within ophthalmology. Key topics include: Optometry; Visual science; Pharmacology and drug therapy in eye diseases; Basic Sciences; Primary and Secondary eye care; Patien Safety and Quality of Care Improvements. This journal is indexed on

Submit your manuscript here: http://www.dovepress.com/clinical-ophthalmology-journal

\section{Dovepress}

PubMed Central and CAS, and is the official journal of The Society of Clinical Ophthalmology (SCO). The manuscript management system is completely online and includes a very quick and fair peer-review system, which is all easy to use. Visit http://www.dovepress.com/ testimonials.php to read real quotes from published authors. 